\title{
Analysis of Product Recalls: Identification of Recall Initiators and Causes of Recall
}

\author{
Kamrul Ahsan \\ Supply Chain Management Discipline, College of Business, Victoria University, Australia \\ E-mail: kamrul.ahsan@vu.edu.au (Corresponding Author) \\ Indra Gunawan \\ School of Engineering and Information Technology, Federation University, Australia \\ Email: indra.gunawan@federation.edu.au
}

\begin{abstract}
Nowadays, product recalls have become an inevitable problem striking companies and manufacturers. If no sufficient preparation is made, product recalls can easily affect the bottom line. The objective of this paper is to analyse product recall notices and identify major issues of recall such as types of recalled products, causes of recall, recall initiators, and the relationship between products, recall initiators and causes of recall. This research provides an in depth analysis of recalls patterns through content analysis of historical recall notices. Analysis shows most food items are recalled due to manufacturing fault, for electrical appliances major causes of recall are design fault, and kids' products are recalled due to design and manufacturing faults, and for all types of products most recalls are initiated by the manufacturer. The result of this research will help manufacturers look at the root causes of recall and find solution to the quality issues of product design and manufacturing. This research can be further extended to incorporate data from various countries.
\end{abstract}

Keywords: Product recalls, reverse logistics, causes of recall

\section{INTRODUCTION}

It would be expected that in today's world, with cutting-edge technology and research and development, defective products could be minimized if not eliminated. In fact, modified competitive, technological, social and political circumstances have magnified the potential impact of operations-related failure (Lewis, 2003). This has made product recalls inevitable in recent times.

Though manufacturers use state-of-the-art operations philosophies, tools and techniques, it is difficult to make the perfect product, and products often need to be recalled. Recalls are a consequence of bad quality products of which the manufacturer was not aware or did not address before distribution and sales. A good example is the large number of car recalls carried out by Toyota in 2009 and 2010 due to floor mat and sudden acceleration problems, which resulted in high recall costs to Toyota and its supply chain members and stakeholders. This recall not only incurred huge litigation fees, but also resulted in estimated losses in billions of dollars of lost sales (Marucheck et al., 2011).

Product recalls can be defined as an action that removes defective products from sale, consumption or operation due to possible safety risk of particular products.
Product recalls are usually due to safety concerns and reasons for recall are mainly due to production fault, design flaw, inadequate instructions and warnings, new scientific information about dangers that may be caused by certain products or materials, accidental contamination and other issues that result in failure to perform intended function for a specified interval under stated conditions (Hora et al., 2011; Bapuji and Beamish 2008; Berman, 1999). Recalls are reverse logistics where recalled products, information, and cash flow are in the opposite direction of the normal supply chain. The process of product recall is cumbersome and members of the entire supply chain are directly or indirectly affected by recalls.

Recalls are initiated by the manufacturer, by retailers or by government, semi-government or private organizations to draw the attention of current users of a product for safety reason. The Wall Street Journal published car recalls data showed that government recall frequencies are less however are typically larger in volume than manufacturer-initiated recalls (Rupp, 2001; Rupp and Taylor, 2002). Research further suggests that recall initiator (government or manufacturer) does not serve as a reliable signal of product quality (Rupp, 2001). However, government-initiated recalls may subsequently damage the reputation of the firm, and a manufacturer-initiated recall campaign may indicate that the firm is standing behind the product and enhancing the reputation of the firm (Rupp, 2001).

Though product recalls occur frequently, research needs to further explore issues related to product recalls. Realizing the importance of product recalls research this study investigates historical recall notices and makes an attempt to provide an insight into recalls trend. This study focuses on historic recall data for New Zealand (NZ) and addresses the following research objectives:

- What are the major types of product recalls?

- Identify the key reasons and factors that determine why certain product recalls appear.

- Find the relationship between recall initiators and the causes of recall.

From historical product recall data, the following factors will be identified: the frequency of product recall incidents for different types of products; who initiated most recalls, and the main reasons for recall. Through a comprehensive literature review on product recalls, this research provides a background and in depth analysis of historic product recall patterns. The paper is organized as follows: in section 2, literature review of the product recalls 
process and previous relevant research is discussed; in section 3, the research methodology and data collection process is described; followed by results and discussion in section 4; finally research summary and future research directions are highlighted in the conclusion.

\section{RESEARCH BACKGROUND}

\subsection{Product Recall Research from Literature}

We conduct a systematic review of product recall articles in the field of reverse supply chain by means of content analysis. The literature pertaining to recall management under a reverse supply chain or reverse logistics context was discovered in databases used by major publishers; Elsevier, Emerald, Springer and Wiley, with a final search of Google Scholar. Only peer reviewed journal articles were considered, published in English, between 1975 and 2013. The publication type was restricted to journal and the journals appropriate to the aforementioned disciplines. Firstly, structured keyword search was carried out in each of the four major databases with "product recalls" and "logistics" or "supply chain" being present in the title, and/or keywords, and/or abstract. Search was then repeated, substituting "marketing" for "supply chain and /or logistics". Upon completion of the search process there were 37 articles belonging to journals displayed in the current sample. Details of number recall articles and their year of publication are shown in Figure 1. Early articles identified recalls as a logistics challenge (Chandran \& Lancioni, 1981), and emphasise how to trace and conduct recalled products (Fisk \& Chandran, 1975), consumer perception on recalls, (Mowen, 1980), and impact of recalls on stakeholders (Jarrell \& Peltzman, 1985). We find that there were only a few articles published until 2000, with the majority of the articles published during the last ten years (i.e. post 2003).

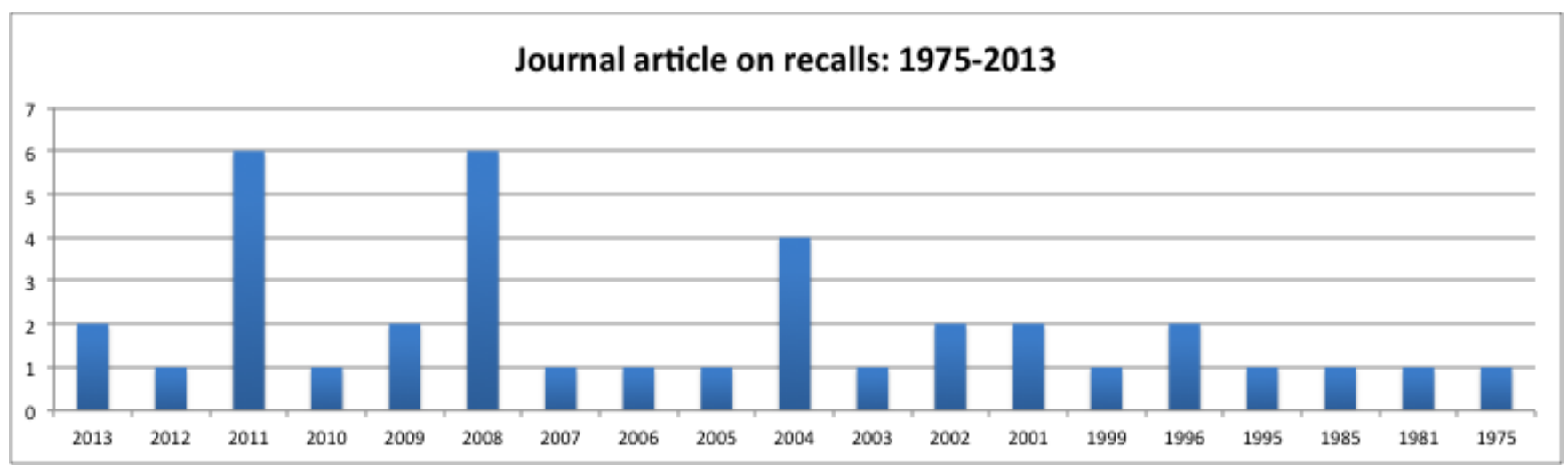

Figure 1. Journal articles on recalls 1975-2013

We analyse different types of recall related research based on the topics covered. Through content analysis of article keywords and abstract from Endnote software, we develop a spreadsheet and find the following results (Figure 2 ). We identify that most of the recalls research are related to product and user safety, and the other most cited topic are recalls cost, recalls in general, and recall planning (Figure 2 ). We find that most previous studies discuss certain types of product categories which are general retail items, automobiles, food and liqour, toys, electrical and pharmaceutical products (Figure 3).

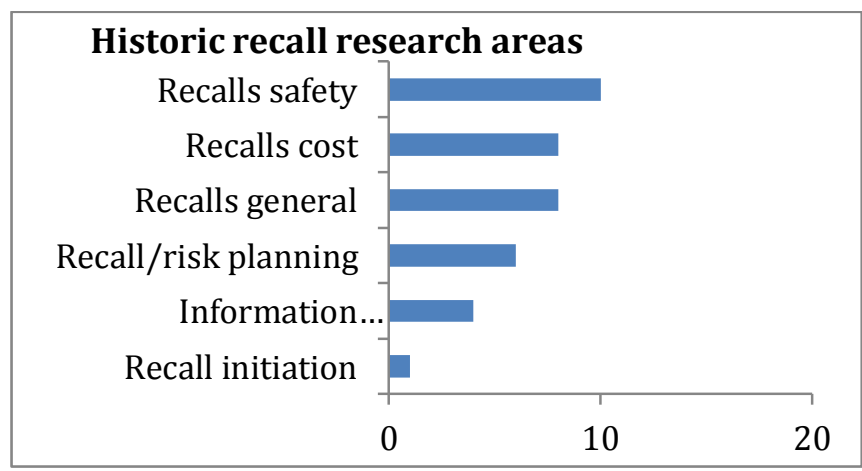

Figure 2. Recall research areas

Analysis of previous research on recalls shows that less research has been conducted in the areas of identifying the elements of recalls, particularly finding the major products recalled, causes of recalls, recall initiators and assured customer services through recall and relationship between these factors.

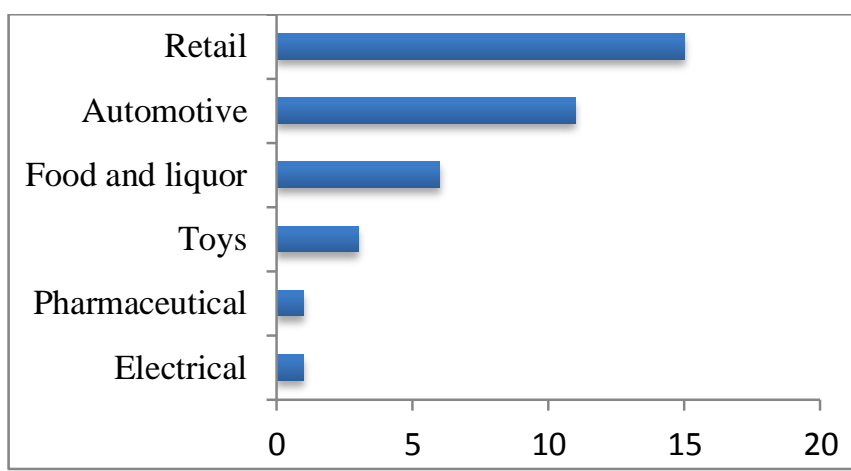

Figure 3. Frequently researched recalled product categories

\subsection{Product Recall Trends}

Recalls for both new and established products occur too often and can have serious consequences. Most recalls research is related to products such as toys, automobile, and food. Major industries dealing with recalls are identified as food, automobiles, pharmaceuticals, medical devices, consumer products and automobiles (Marucheck et al. 2011). From Figure 3 we can also see most of the previous research on recalls mainly relate to automobiles, food and liquor, and toys.

Product recalls are increasing in frequency and volume. In 1988, the U.S. Consumer Product Safety 
Commission was involved in some 221 recalls frequencies covering about 8 million product units. Five years later in 1993 , those numbers had risen to 367 recalls covering about 28 million product units. In the case of automobiles in 1966, 58 recalls were issued. In 2000, the number of recalls issued had increased to 631, and by 2008 they were close to 800 . The total number of recalls from 1988 to 2001 was 5,233 (Bae \& Silva, 2011). Analysis of car recall data shows that while every carmaker has experienced recalls, the majority of recalls are initiated by only a few carmakers (Ahsan, 2010). Ahsan (2013) identifies trends of US car recalls from historical data (2000-2010) and research shows that every carmaker conducts recalls with the average frequency of recalls being 3.5 per month. Based on registered data of 23.1 million vehicles in the UK between 1992 and 2002, Bates et al. (2007) identify that car recall rates are increasing. Research also shows that there are substantial differences in recall rates between different car manufacturers; European and American producers have nearly three times greater recall rates than their East Asian counterparts. Teratanavat and Hooker (2004) identify characteristics of US meat and poultry recalls during 1994-2002 and point out the reasons for meat and poultry recalls, and how recall problems were identified. Some high profile food product safety incidents include 'mad cow disease in the UK' during 1986-1987, 'salmonella outbreak in peanut butter paste in the US and Canada' during 2008-2009, 'melamine in infant's formula produced by Chinese company San-lu' (Marucheck et al., 2011). Among remarkable toy recalls, Mattel's recalls due to lead-paint hazards for children in 2007, and Mattel/Fisher Price recalls in 2010 have made news. About 11 million tricycles, toys and high chairs were recalled due to safety hazards. A further, 100,000 toys were recalled due to choking hazard (Marucheck et al., 2011).

Recent recalls of numerous products in multiple industries suggests that firms are not immune to product recalls (Hora, Bapuji, \& Roth, 2011). Product recalls are important to interrelated supply chain parties that include customer; manufacturer, distributor, government, and others. Customers are affected by recalls as they are users of the product and product safety and security issues are involved. Manufacturers or distributors are concerned with quality assurance, goodwill, reputation and responsibilities and long run customer service issues related to recalled product returns or disposition.

\subsection{Recalls Process and Causes of Recalls}

Product recalls are a reverse distribution activity that withdraws goods from customers or from selling locations. A product recall seeks to withdraw the product from the market.

The products are either hazardous or defective, are not according to specification, or do not comply with government compliances. The recall process typically entails an official announcement outlining the reason for the recall and a remedy offered to the customer (Hora et al., 2011). Reasons for recalls include issues such as nonconformance to quality, not maintaining some specific standard or specification, or lack of safety (Beamish \& Bapuji, 2008; Lyles, Flynn, \& Frohlich, 2008). Voluntary safety-related recalls are the responsibility of the supplier (Product Safety Recall Australia, 2013). If product related problems are encountered by customers, customers inform the retailer or local supplier, or the manufacturer. When many customers encounter the same problem, the manufacturer (or sometimes a government authority) investigates the issue, makes a recall decision and informs respective customers and stakeholders. If manufacturers do not recall or do not respond to customer complaints, then the government authority may investigate further. If government experts find a safety standard violated, they contact the manufacturer, who initiates the recalls process. Sometimes, if product specifications do not match with government safety regulations, government initiate manufacturers to recall the product from the market. Government initiated recalls follow a series of investigation stages, however at any point in the investigation process the manufacturer can opt to conduct a recall (Rupp, 2004). On rare occasions, manufacturers do not agree with the decision of the government and bring the issue to court. Once recalls are announced, manufacturers send notice letters to customers and announce the recall through the media so that the product can be brought in and the issue resolved. After careful investigation of several historical car recalls, this research identifies and shows a generic recalls process in Figure 4.

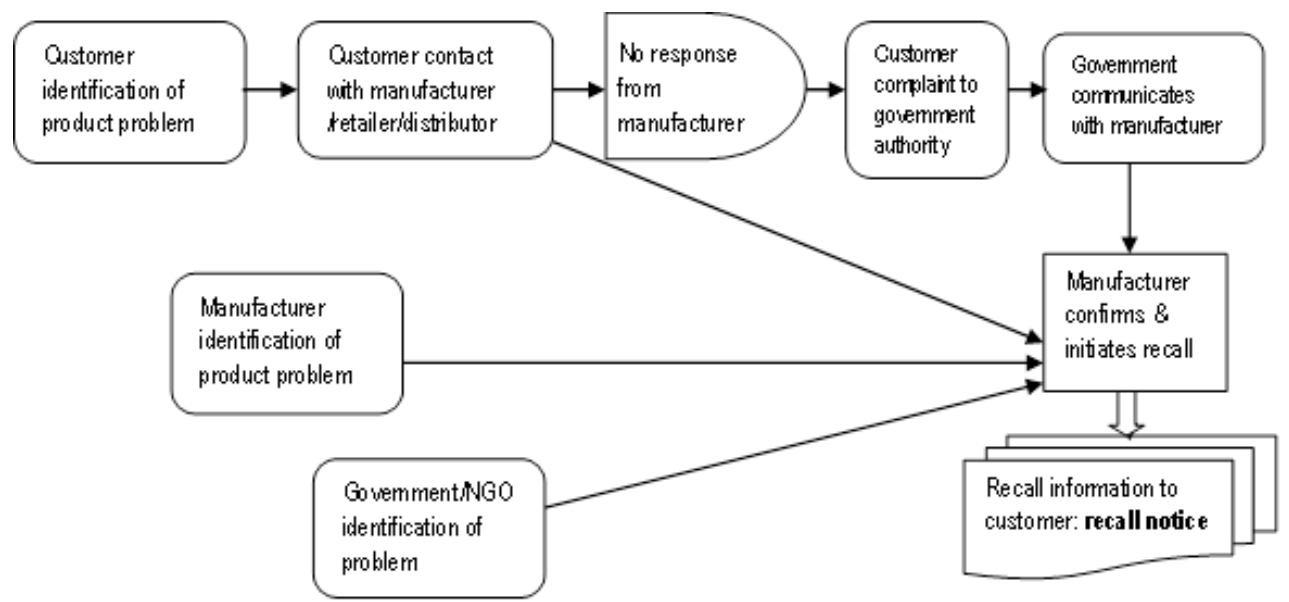

Figure 4. A generic recall process

The whole process of recall is lengthy. There are many steps before a final recall decision is made (Bae \& Silva, 2011).
Sometimes manufacturers take time to respond to customer complaints and some cases end up in court and the 
respective government authority deals with the manufacturer to come to a settlement compensation for customers. A good example of lengthy recall process includes the Ford Motor and Firestone Tyre recall 2000. The NHTSA received letters from Ford Explorer owners in the USA from the early 1990s. In July 1998, the NHTSA received data from insurance companies regarding 21 cases of Firestone tyres for Ford Explorer accidents. After receiving more complaints the NHTSA announced a formal defect investigation into 47 million TAX, ATXII and Wilderness tyres manufactured by Firestone (Moll, 2003). The Firestone tire recall that affected Ford vehicles took more than seven years from the first report until a final decision was reached. The recent increase in product recalls has shifted attention from why products are recalled to why it takes so long to recall defective product that pose safety hazards (Hora et al., 2011).

\subsection{Call for Recalls}

Recall notice is a formal announcement from the manufacturer or government authority regarding product safety. A recall notice usually contains information such as: who is recalling the product, what the product is, and what is wrong with the product, possible action to be taken by consumers (safety or warning message for use or consumption of the product, including where to return, repair, or replace the product), where the product can be found or sold, and who to contact for further enquiries. Following the recalls notice, the retailer or distributor or manufacturer needs to organize and support logistics, technical, financial, and legal issues related to recalled products and affected customers.

Research shows that preventive or voluntary recall strategy takes a longer time to recall compared to reactive (or involuntary) recall strategy (Hora et al., 2011). Voluntary recalls are initiated by proactive manufacturers who suspect a defect or have some concern regarding product quality and reliability. For example in the US auto industry, recalls are considered manufacturer-initiated or voluntary if NHTSA has not opened a defect safety investigation prior to the company's decision to conduct recalls (Rupp \& Taylor, 2002). Involuntary or reactive recalls are forced; due to non-compliance issues or when multiple customer complaints regarding some product, or a government agency enforces a company to initiate a recall. For example, in case of Ford Motor and Firestone Tyre recalls, government recalls follow a series of investigation stages. Research shows that the recall initiator (either the government or the manufacturer) does not serve as a reliable signal of product quality and investors should not make equity on the basis of who initiated the safety recall (Rupp, 2004).

Recalls occur when the customer or the manufacturer or the government safety ensuring authority identifies a serious product defect or fault as a health hazard or as risky to use. Product recalls notices are provided by manufacturers, retailers or by government, semi-government or private organizations to draw attention of current users of products for safety reason. Recall notices are usually archived by government, semi-government or private organizations. These organizations maintain websites to provide up-to-date product recall information for all stakeholders, and make information available to the public. For example, US consumer product recall information is archived by the Consumer Product Safety CommissionCPSC, and car recalls are initiated by the National Highway Traffic Safety Administration (NHTSA).

In New Zealand (NZ), different organisations are monitoring or recording different types of product recalls (Table 1). The Consumer Affairs Ministry, NZ supports responsible suppliers in recalling products which fall below quality or safety standards, or where a safety issue has been identified. This organisation publishes all recall notices that are brought to their attention and fall into the general category of product safety. The Ministry publishes recall notices for information purposes. However, other respective organizations also conduct recall notices for a particular group of products. For example, NZ Transport Agency conducts only car recalls. Food recalls at the trade or consumer level are conducted by the Ministry of Primary Industries. Medsafe online keeps records of medicine and medical device recalls. An independent non-profit organisation known as Consumer NZ, established in 1959, keeps record of all recalls conducted by NZ Consumer Affairs ministry.

Table 1. Organisations monitoring or recording recalls in $\mathrm{NZ}$

\begin{tabular}{|l|l|l|}
\hline \multicolumn{1}{|c|}{ NZ Authority } & \multicolumn{1}{|c|}{ Role } & \multicolumn{1}{c|}{ Website } \\
\hline $\begin{array}{l}\text { Ministry of } \\
\text { Consumer } \\
\text { Affairs }\end{array}$ & $\begin{array}{l}\text { Recall of all products } \\
\text { within NZ. }\end{array}$ & $\begin{array}{l}\text { (http://www.consumeraff } \\
\text { airs.govt.nz) }\end{array}$ \\
\hline $\begin{array}{l}\text { Ministry of } \\
\text { Primary } \\
\text { Industries }\end{array}$ & $\begin{array}{l}\text { Recall only food } \\
\text { products. }\end{array}$ & $\begin{array}{l}\text { http://www.foodsmart.go } \\
\text { vt.nz/food- } \\
\text { safety/recalls/latest- } \\
\text { recalls/ }\end{array}$ \\
\hline $\begin{array}{l}\text { NZ Transport } \\
\text { Agency }\end{array}$ & $\begin{array}{l}\text { Provides vehicle related } \\
\text { safety recalls. The } \\
\text { recalls notices are } \\
\text { developed with the } \\
\text { Motor Industry } \\
\text { Association and the } \\
\text { safety.nzta.govt.nz/ }\end{array}$ & \\
& $\begin{array}{l}\text { Ministry of Consumer } \\
\text { Affairs. }\end{array}$ & \\
\hline Medsafe Online & $\begin{array}{l}\text { Keeping record of } \\
\text { medicine and medical } \\
\text { Revice recalls in NZ }\end{array}$ & http://www.medsafe.govt \\
since 1 July 2012. & ormation \\
& $\begin{array}{l}\text { Keeps record of all } \\
\text { recalls conducted by } \\
\text { Ministry of Consumer }\end{array}$ & http://www.consumer.org \\
Affairs NZ. & nz/recalls \\
\hline Consumer NZ & \\
\hline
\end{tabular}

\subsection{Impact of Recalls and Recall Classification Scheme}

The magnitude of a recall's negative impact on company performance varies by recall severity, firm size, and remedy to recall (Chen, Ganesan, \& Liu, 2009; Salin \& Hooker, 2001; Thomsen \& McKenzie, 2001). Product recalls due to lack of safety highlight quality failures that can be expensive for companies. Consumers react negatively to recalls unless the recalling company acts proactively and in a socially responsive manner (Hora et al., 2011). Choi and Lin (2009) analyse consumer response to crisis and safety in regards to the 2007 Mattel product recalls and how mass media 
covered the same recall. Research finding the link between automakers reputation with recalls shows that firms with a stronger reputation experience a higher reduction in their market value than do firms with a weaker reputation (Rhee \& Haunschild, 2006). Rupp (2001) investigates impact on stock market returns to both manufacturer and government initiated recall based on empirical research on the basis of the Wall Street Journal and NHSTA data. Companies are still not prepared to deal with recalls nor do they recognize how great an impact recalls can have on an organization's reputation. The risks are higher than ever for companies that fail to anticipate the possibility of a product recall (Monczka \& Trent, 1995).

The cost of recalls is enormous for all parties in the chain. Product recalls due to safety hazards entail social costs, such as property damage, injury, and sometimes death (Hora et al., 2011). Costs of product recall through the reverse distribution channel are at least two or three times higher than costs incurred in forward distribution, often due to small quantities of shipments, fluctuating and uncertain demand, and the urgency involved in the recall process (Chandran \& Lancioni, 1981; Jayaraman, Patterson, \& Rolland, 2003). Costs to customers sometimes amount to death or physical disability. For the manufacturer, costs are quite substantial. The cost function can be the cost of recall operations, cost of product replacement or repair, cost of losing market share or goodwill, cost of marketing the brand value, cost of lawsuit settlements, and cost of closing share price (Berman, 1999; Gomer, 2008; Jamal, 2004; Khan and Sarker, 2002; Mabini, 1992).

With respect to severity and impact on customers, recalls can also be classified as class I, II and III (Kumar \& Budin, 2006). Class I is the most severe, in this category the use of, or exposure to the product will cause serious, lasting adverse health problems or death. Bae and Silva (2011) identify that recalls classified as hazardous are more effective in reducing accidents. Class II types of recall may cause temporary health consequences. Lastly, class III, is the least serious type of recall, and generally does not involve any adverse health consequences. Recalls are classified as either voluntary or preventive, and involuntary or reactive (Kumar and Budin, 2006; Hora et al., 2011).

\section{RESEARCH METHODS AND DATA COLLECTION}

This study focuses on content analysis method as a research tool. Our unit of analysis is archival product recall notice. Content analysis is a research technique that enables inferences to be made based on a text considering the context in which it was written (Krippendorff, 2004). The method basically includes two separate though usually integrated approaches, namely qualitative and quantitative content analysis (Krippendorff, 2004). Qualitative content analysis demands meticulously reading each document, and understanding and interpreting the text in its relevant context. On the other hand, quantitative content analysis summarizes the inferences and insights derived from the qualitative phase in the form of numerical examinations of the interpreted text units and the related categorized codes (Krippendorff, 2004). The study utilises qualitative and quantitative techniques in an integrated manner. We use the following content analysis steps: (1) locate source of historical recall data (2) collect recall notice, (3) search recall notice element information, (4) code and analyse frequency of relevant qualitative data.

This research is based on secondary data from recall notices archived by New Zealand Consumer's organisation. Product recall cases that occur in New Zealand from the year 2007 to 2009 are collected from www.consumer.co.nz. All product recall cases that occur within New Zealand are announced in this website to alert consumers concerned regarding quality and reliability of products.

There are several advantages to using this data for research into recalls. Primarily, because of the authenticity of the information, and also since data is widely available from a source. Furthermore, data sourced from archives is more objective than primary survey data as it is free from contamination by respondent perceptions and memories of the phenomenon of interest (Calantone \& Vickery, 2009).

In total we collect 172 recall notices over a three year period (2007-2009). The recall data are grouped into 5 major product types: food items, kids product, electrical appliances, automotive, and others. The important issues collected on the recalled products are date of recall, product type/category, recall initiator (retailer, manufacturer or government), cause of recall (design flaw, manufacturing fault, or mislabelling - Beamish and Bapuji, 2008; Lee et al. 2008; Lyles et al. 2008; Geistfield, 2009), customer service assurance or action to be taken by customer (return to retailer, return to manufacturer, refund), other details (tracking number, where it was sold). Details of data consistency can be obtained from the tables in the next section.

\section{RESULTS AND DISCUSSION}

Based on collected data, analysis is made on statistics of product recalls. Figure 5 shows the frequency of recall from 2007 to 2009. During the study period, most recalled products are classified as food items, kid's product, electrical appliances, automotive and others (Figure 6). Among the recalled products majority of products are food items, electrical appliances and kid's products. Because of the small local market, automotive recalls are not remarkable.

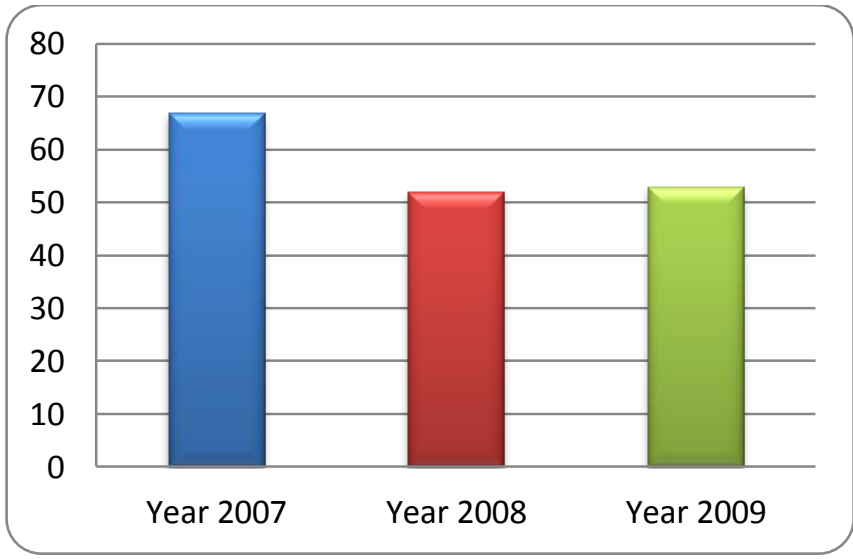

Figure 5. Product recall frequency from 2007 to 2009 


\section{Recall frequency for different products} (2007-2009)

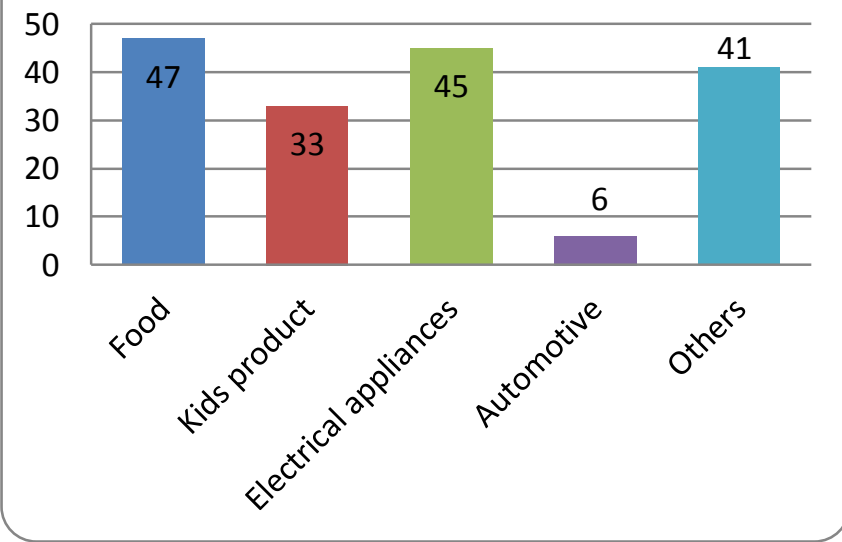

Figure 6. Product recall frequency by type of product from 2007 to 2009

Due to limited data range of product recalls, the trend and behaviour of product recall frequency is difficult to observe, but it is believed that the trend is not consistent as product recalls are quite a random phenomenon that may strike any company or manufacturer. However, product recalls must be considered by every company and contingency plans of risk management need to be made prior to product release in the market. Min (1989) stated that "without preparation for the possible occurrence of product recalls, a company may panic when a product recall actually takes place".

\subsection{Causes of Recall}

Product defect is one of the main causes of recall. Hora et al. (2011) categories these defects as manufacturing defects, design flaws, and inconsistent/improper instruction and warnings finishing, or packaging. Recall data shows major recalls are due to product design flaws, manufacturing faults, and mislabelling (Figure 7). The findings of this study are similar to previous research on car recalls that find most product recalls occur due to design or manufacturing problems (Beamish and Bapuji, 2008). Some researchers identify that design-related recalls are increasing proportionately faster than manufacturing occurs (Beamish and Bapuji , 2008; Dowlatshahi, 2000).

Product design occurs prior to manufacturing and starts in the research and development phase. Design flaws are related to product design, materials selection etc. The gas tank in the 1970s Ford pinto stands out as an example of a design flaw with the car, where engineers designed the gas tank 'behind the rear axle rather than above the axle' (Schwartz, 1991). The location of the gas tank along with other features of the car created a hazard and the model was recalled.

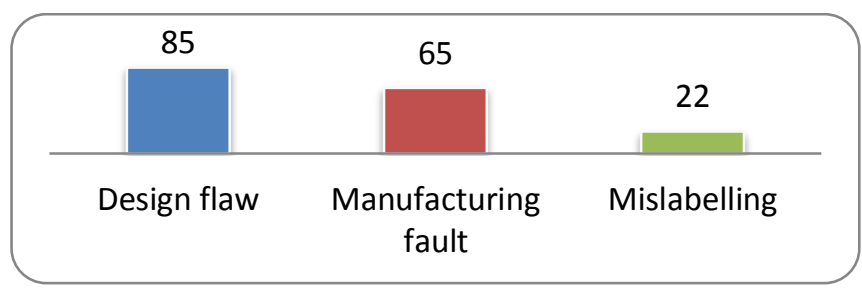

Figure 7. Causes of product recall (Year 2007-2009)
Firms use multi-partner manufacturing processes where manufacturing defects can be tracked back to supplier and contract manufacturers. In case of recalls, it is comparatively quicker to track back the design process compared to the multi-partner manufacturing process. On the other hand, Hora et al. (2011) argue that because of internalization of product design, product recalls resulting from design flaws may serve as an indication of admission of firms mistakes, and for that reason may take longer to track exact design faults in the product. As a potential cause of manufacturing fault of recalls, a company's strategy of shifting out of control overseas manufacturing processes are to be blamed (Marucheck et al. 2011). Because of supply chain complexities, companies are struggling to maintain product design quality and safety in international production networks, and at the same time they are trying to cut costs and shorten the concept-to-market time (Zhu et al. 2009). The massive Toyota recall in 2010 is attributed as an example of the case of over expansion of international production networks, not because of quality and safety (Maruccheck et al., 2011).

The number of mislabelling related recalls in our data are $22(13 \%)$. The Erickson Research Group study finds that $68 \%$ of recalls are related to incorrect labeling and packaging. Product instructions, specifications and warnings are informational problems, and with this type of defect (mislabelling) the product does not have adequate warnings about the product risk (Geistfeld, 2009).

One important finding from the analysis is the cause of recalls that occurred from 2007 to 2009 . It can be seen from Figure 7 that the most major causes of product recall are due to design flaw and manufacturing fault. This gives an important indication that in order to overcome and prepare for a possible product recall; measures should be started from the beginning stages of product design and continued to the production process of the product. Even with current sophisticated product design technology, it is still unlikely manufacturing companies will always produce defect-free goods.

\subsection{Relation between Recalled Products and Causes of Recall}

We further cross examine the causes of recall for different type of recalled products (Table 2). Analysis shows most food items are recalled due to manufacturing and labelling faults. For electrical appliances major cause of recall is design fault. Whereas, kids products are recalled due to both design and manufacturing faults.

It is remarkable to mention that mislabelling issues are predominant for food items, compared to other types of products. Our findings on mislabeling issues are in line with the Erickson Research Group study, they found that $68 \%$ of food item recalls are related to incorrect labeling and packaging and $15 \%$ of businesses have inadequate label review policies (Kumar and Budin, 2006). Previous research identifies that the majority of kids toy recalls are because of design flaws (Beamish and Bapuji, 2008). Our research identifies that for kids products (including toys) majority of the recalls are due to design and manufacturing fault. 
Table 2. Types of products and causes of recall

\begin{tabular}{|c|c|c|c|}
\hline \multirow{2}{*}{ Product types } & \multicolumn{3}{|c|}{ Causes of recall } \\
\cline { 2 - 4 } & Design & Design & Design \\
\hline Food & 1 & 1 & 1 \\
\hline Kids product & 15 & 15 & 15 \\
\hline Electrical appliances & 41 & 41 & 41 \\
\hline Automotive & 5 & 5 & 5 \\
\hline
\end{tabular}

\subsection{Who Initiated the Recalls, for Which Products and Why?}

Figure 8 on the other hand, shows who initiated most of the recalls throughout the three year period. Most product recalls are initiated by the manufacturers themselves. Therefore, in terms of resources and costs associated with product recalls, these are borne mostly by the manufacturers. Thus, it is very important to plan and prepare for a possible product recalls in order to optimize all the recall expenses. Our study finds retailers have conducted 40 (23\%) of the recalls. The reasons may include that manufacturers are not within the country and retailers take responsibility of the product.

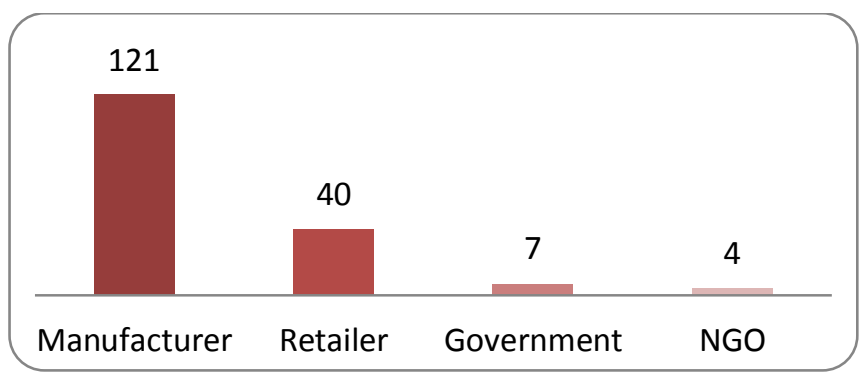

Figure 8. Recall initiator from year 2007-2009

Table 3 describes product recalls in conjunction with recall initiators and causes of recall. As can be observed from Table 3 and Figure 7, main recall initiators are manufacturer and retailer. Design flaw and manufacturing fault are the major causes of recalls for manufacturer, whereas design flaw is the main cause of recalls for retailer. There are only a few cases of product recalls initiated by government and non-government organisations.
Table 3. Recall initiators and causes of recalls during 20072009

\begin{tabular}{|c|c|c|c|}
\hline \multirow{2}{*}{ Initiator } & \multicolumn{3}{|c|}{ Causes of recalls } \\
\cline { 2 - 4 } & Design fault & $\begin{array}{c}\text { Manufacturing } \\
\text { fault }\end{array}$ & Mislabelling \\
\hline Manufacturer & 56 & 52 & 13 \\
\hline Retailer & 27 & 9 & 4 \\
\hline $\begin{array}{c}\text { Government } \\
\text { and NGO }\end{array}$ & 2 & 4 & 5 \\
\hline
\end{tabular}

We further summarise types of product recall, causes of recalls, and recall initiator and develop a hypothised recall model showing the link between these elements (Figure 9). Bold marked lines shows more weight in terms of relationship between the items.

\section{CONCLUSION}

This research considers product recalls as an inevitable problem for supply chain members and emphasises an understanding of recalls. Through a comprehensive literature review on product recalls, we propose a generic recall process and conduct an in depth analysis of historic product recalls.

This study focuses on recall data in New Zealand. We identify the frequency of product recall incidents for different types of products; who initiated the majority of recalls, the main reasons of recall, and relation between recall initiators and causes of recall. We find the majority of recalled products are food items, electrical appliances, and kid's products. Recall data shows major recalls are due to product design flaw, manufacturing fault, and mislabelling. Analysis also shows most food items are recalled due to manufacturing and labelling faults, and for electrical appliances major causes of recall are due to design fault. This gives an important indication that in order to overcome and prepare for a possible product recall; measures should be started from the beginning stages of product design up to the production process of the product. Even with sophisticated product design technology, and six sigma quality target, it is still unlikely manufacturing companies will always produce defect-free goods.

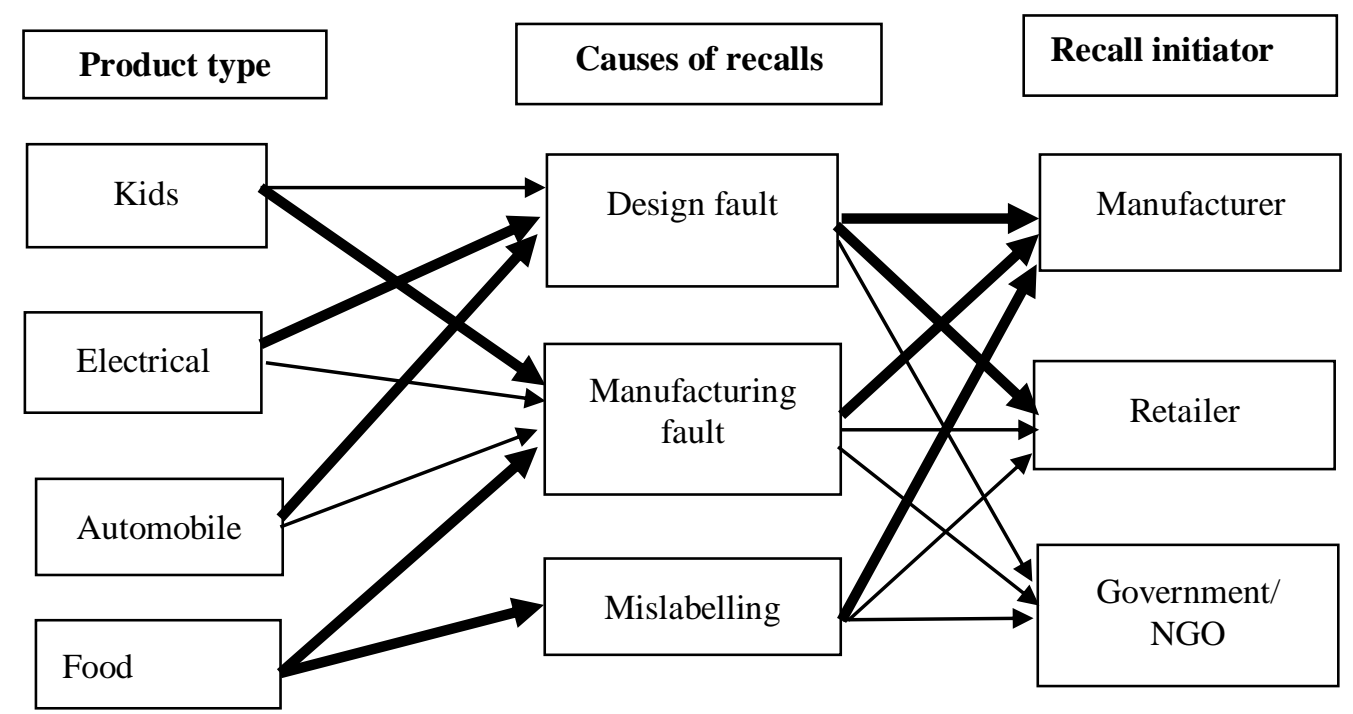

Figure 9. Relationship between recalled product, causes of recall and recall initiator 
In the case of food products, if recall was due to contamination, obviously there is no question of remanufacture; the only option is to dispose of the product. Therefore, it is important to consider disposal inventory model for product recall with products that cannot be reworked or remanufactured. Inventory management would help in inventory planning and decision for a product recall in order to conduct a successful recall.

We find the main recall initiators are the manufacturers. Therefore, resources and costs associated with product recalls are mostly borne by the manufacturer. It is very important for manufacturers to plan and prepare for possible product recalls in order to optimize recall expenses. Our study also finds retailers initiate the second highest number of recalls. There are only a few cases of product recalls initiated by government and non-government organisations. Our study findings of recall initiators vary slightly from Rupp (2001) whose study was based on US car safety recalls. Both studies identify manufacturers as the main initiator of car recalls. Rupp (2001) identifies that the government initiates larger volume of recalls with less frequency. We find retailers are the second main initiators, and the government conducts the least recalls, as manufacturers are not within the country and retailers take responsibility for the product.

Knowledge of recall initiators and causes of recall will help to develop a proactive measure to reduce the number of recalls. Identification of recalls initiators show the who usually takes responsibilities or initiatives of recalls, and this identification will further help the government and other stakeholders to identify, press or guide the recall. Moreover, insights gained from the recalled returned products can help the manufacturer in future product designs, improvements in customer service, or reductions in returns (Hsiao, 2010).

Further, we cross examine the causes of recall, with type of recalled product and recall initiator. From analysis the following conclusions can be drawn:

- Most food items were recalled due to manufacturing fault.

- For electrical appliances major causes of recalls were due to design fault.

- Kids' products were recalled due to design and manufacturing faults.

- For the product categories of food, electrical appliances, and kids products, in the majority of cases the manufacturer initiated the recall.

The possibility of product recalls must be consider by every company and, preparation plans and risk management made prior to the product being released on the market. Supply chain members, especially manufacturers, distributors and retailers must prepare for recalls. For food product recalls, the first priority should be the health and well-being of customers; followed by refund and disposal of recalled items. For electrical item recalls, the major logistics issues are related to identification of customers, and repair or replacement of the recalled product, or refunding money to the customer. For kid's products, major concerns are the safety and security of the customer and the major logistics issues are refund, repair, and replacement of the recalled item.

One important issue of recalls is the traceability of recalled products, or product users and product location in production line. Proper identification of manufacturing fault of recalls can help manufacturers to stop the production line of that particular product instead of pursuing massive recalls of entire quantity of product. Sometimes location of the manufacturer is difficult to identify because of the complexity of the supply chain.

When a small quantity of product is defective, the cost to recall the product is very high. Usually, for small volumes of defective products, manufacturers will only recall the product and remove the product from the market, and no reworking or remanufacturing will be done. However, this depends on the type of product.

Historic product recalls data for a three year period in New Zealand are analysed due to the availability of archival data. Further research can be done to incorporate more data from recent years and also to add product recalls data from Australia since New Zealand and Australia have common business. Moreover, further empirical research can be conducted to test the proposed relationship model between types of product recalls, causes of recall and recall initiator.

\section{REFERENCES}

Ahsan, K. (2010), Understanding trends of car recalls. The IEEE International Conference on Industrial Engineering and Engineering Management (IEEM 2010), pp. 1123-1127.

Ahsan, K. (2013), Trend analysis of car recalls: evidence from the US market. International Journal of Managing Value \& Supply Chains, 4(4), pp. 1-16.

Bae, Y.K. \& Benítez Silva, H. (2011), Do vehicle recalls reduce the number of accidents? The case of the US car market, Journal of Policy Analysis and Management 30(4), pp. 821-62.

Bates, H, Holweg, M, Lewis, M \& Oliver, N. (2007), Motor vehicle recalls: Trends, patterns and emerging issues, Omega, 35(2), pp. 202-10.

Beamish, PW \& Bapuji, H. (2008), Toy recalls and China: emotion vs. evidence, Management and Organization Review, 4(2), pp. 197-209.

Berman, B. (1999). Planning for the inevitable product recall, Business Horizons, 42(2), pp. 69-78.

Calantone, R \& Vickery, SK (2009), Special topic forum on using archival and secondary data sources in supply chain management research, Journal of Supply Chain Management, 45(2), pp. 94-95.

Chandran, R \& Lancioni, RA (1981), Product recall: a challenge for the 1980s, International Journal of Physical Distribution \& Logistics Management, 11(8), pp. 46-55.

Chen, Y, Ganesan, S \& Liu, Y (2009), Does a firm's product-recall strategy affect its financial value? An examination of strategic alternatives during productharm crises, Journal of Marketing, 73(6), pp. 214-226.

Choi, Y \& Lin, Y-H (2009), Consumer response to crisis: Exploring the concept of involvement in Mattel product recalls, Public Relations Review, 35(1), pp. 1822.

Dowlatshahi, S. (2005), A strategic framework for the design and implementation of remanufacturing operations in reverse logistics, International Journal of Production Research, 43(16), pp. 3455-3480. 
Eagle, L, Rose, LC, Kitchen, PJ \& Hawkins, J. (2005), Regulatory oversight or lack of foresight? Implications for product recall policies and procedures, Journal of Consumer Policy, 28(4), pp. 433-460.

Geistfeld, M.A. (2009), Efficiency, fairness and the economic analysis of tort law. In: White, M.D. (Ed.), Theoretical Foundations of Law and Economics. Cambridge University Press, New York, NY.

Gomer, F. (2008), Recalls...when Supply Chain Management turns into Crisis Management, Supply Chain Asia, pp. 24-6.

Haunschild, PR \& Rhee, M (2004), The role of volition in organizational learning: the case of Automovitve Product Recalls, Management Science, 50(11), pp. 1545-1560.

Hsiao, JMM (2010), Building Competitive Advantage Through Innovative Reverse Logistics Capabilities, Operations and Supply Chain Management 3(2), pp. $70-82$

Hora, M, Bapuji, H \& Roth, AV. (2011), Safety hazard and time to recall: The role of recall strategy, product defect type, and supply chain player in the US toy industry, Journal of Operations Management, 29, pp. 766-777.

Jamal, A. M. M., Sarker, B. R. and Mondal, S. (2004), Optimal manufacturing batch size with rework process at a single-stage production system. Computers \& Industrial Engineering, 47, pp. 77-89.

Jayaraman, V, Patterson, RA \& Rolland, E. (2003), The design of reverse distribution networks: models and solution procedures, European Journal of Operational Research, 150( 1), pp. 128-149.

Jarrell, G., \& Peltzman, S. (1985), The impact of product recalls on the wealth of sellers. Journal of Political Economy, 93, pp.512-536.

Khan, L. R. \& Sarker, R.A.(2002), An optimal batch size for a JIT manufacturing system. Computers \& Industrial Engineering, 42, pp.127-136.

Krippendorff, K. (2004), Reliability in content analysis, Human Communication Research, 30 (3), pp. 411-433.

Kumar, S. \& Budin, E.M.(2006), Prevention and management of product recalls in the processed food industry: a case study based on an exporter's perspective, Technovation, 26(5-6), pp. 739-750.

Lee, H, Tseng, M \& Hoyt, D. (2008), Unsafe for children: Mattel's toy recalls and supply chain management, Stanford Graduate School of Business, case no. GS63.

Lyles, M.A., Flynn, B.B. \& Frohlich, M.T. (2008), All supply chains don't flow through: understanding supply chain issues in product recalls, Management and Organization Review, 4( 2), pp. 167-182.

Lewis, M.A. (2003), Cause, consequence and control: towards a theoretical and practical model of operational risk. Journal of Operations Management, 21, pp. $205-224$.

Mabini, M.C., Pintelon, L.M., \& Gelders, L.F. (1992), EOQ type formulations for controlling repairable inventories, International Journal of Production Economics, 28, pp. 21-33.

Marucheck, A., Greis, N., Mena, C. \& Cai, L.(2011), Product safety and security in the global supply chain: Issues, challenges and research opportunities, Journal of Operations Management, 29, pp. 707-720.

Monczka, R.M. \& Trent, R.J. (1995), Purchasing and sourcing strategy: trends and implications, Center for Advanced Purchasing Studies, Tempe, Arizona.

Moll, R.(2003), Ford Motor Company and Firestone tyre recall, Journal of Public Affairs, 3(3), pp. 200-211.

Min, H. (1989). A bicriterion reverse distribution model for product recall. OMEGA, 17(5), pp $483-490$.

Product Safety Recall Australia (2013), retrieved from http://www.productsafety.gov.au.

Rupp, N.G.(2004), The attributes of a costly recall: evidence from the automovtive industry, Review of Industrail Organization, 25, pp. 21-44.

Rupp, N.G. \& Taylor, C.R. (2002), Who initiates recalls and who cares? Evidence from the automotive industry, Journal of Industrial Economics, 1( 2), pp. 123-149.

Rupp, N.G. (2001), 'Are government initiated recalls more damaging for shareholders? Evidence from automotive recalls, 1973-1998', Economics Letters, 71(2), pp. 26570.

Rhee, M. \& Haunschild, P.R. (2006), The liability of good reputation: A study of product recalls in the US automobile industry, Organization Science, 17( 1), p. 101.

Salin, V. \& Hooker, N.H. (2001), Stock market reaction to food recalls, Review of Agricultural Economics, 23(1), p. 33.

Schwartz, G.T. (1990), 'The myth of the Ford Pinto case', Rutgers Law Review, 43, p. 1013.

Teratanavat, R. \& Hooker, N.H. (2004), Understanding the characteristics of US meat and poultry recalls: 19942002, Food Control, 15(5), pp. 359-367.

Thomsen, M.R. \& McKenzie, A.M. (2001), Market incentives for safe foods: an examination of shareholder losses from meat and poultry recalls, American Journal of Agricultural Economics, pp. 526538.

Zhu, Y., You, J., Alard, R. \& Schönsleben, P. (2009), Design quality: a key to improve product quality in international production network, Production Planning and Control, 20 (2), pp. 168-77.

Kamrul Ahsan, $\mathrm{PhD}$ is a senior lecturer in supply chain management, at the College of Business, Victoria University, Australia. His current research areas include reverse logistics, humanitarian logistics management, sustainable procurement, supply chain integration and project performance management. Dr. Ahsan has been increasingly recognized by the research and professional community and his publications have appeared in many peer-reviewed journals. Recently, he has received the Project Management Institution New Zealand (PMINZ) 2011 research achievement award. His co-authored article on remanufacturing was selected as best paper award in the 21st International Conference on Production Research (ICPR 21), 
2011 in Stuttgart, Germany. He is on the editorial board member of several international supply chain and project management journals.

Indra Gunawan, $\mathrm{PhD}$ is a senior lecturer and coordinator of Maintenance and Reliability Engineering Programs, School of Engineering and Information Technology, Federation University Australia. He obtained his PhD in Industrial Engineering from Northeastern University, USA. His main areas of research are reliability engineering, production and operations management, application of operations research, applied statistics, probability modeling, and project management. His work has appeared in many peer-reviewed journals and international conferences. 